\title{
Caterpillar Complex: A Rise in Threat to Mango Panicle
}

\author{
J. Nayanathara and R. Narayana \\ Department of Agricultural Entomology, College of Agriculture, Vellayani, Kerala Agricultural University \\ Thiruvananthapuram-695 522, India \\ E-mail: jnayanathara@gmail.com
}

\begin{abstract}
The lepidopteran pest complex sheltering in the mango panicle is a rising threat to production and productivity. The caterpillar complex causing menace to the reproductive phase of the crop is collected, reared and documented for further studies. The samples of infested panicle were collected from four random districts of Kerala and 17 specimens belonging to 7 families of Geometridae, Lycaenidae, Torticidae, Nolidae, Noctuidae, Erebidae and Crambidae were recorded.
\end{abstract}

Keywords: Lepidoptera, Pest, Mango, Inflorescence

Mango; the marvel fruit from family Anacardiaceae has been plagued by several primary, secondary, occasional and key pests (Dangi et al 2017). In the Indian scenario, about 250 insect and other mite pests were recorded. Only about 30 insect species among these were found to cause a serious threat to the yield (Kapadia 2003). The reproductive and vegetative stages of the plants are prone to severe pest and disease infestations. In recent times, heavy toll of lepidopteran incidence in the panicle is a rising concern among the growers. The obscure nature of damage by a plethora of polyphagous caterpillar complex in panicle went unnoticed for a quite long period. The ravage in infestation level anticipated a surge in pest status of these caterpillars in near future to reach an outrageous extend (Jayanthi et al 2018). Since flowering is a decisive element concerning the mango production, a particular focus needs to be made on pests affecting this stage of growth. Considering this aspect, the study was programmed with the aim of documentation of various caterpillar pests infesting the mango inflorescence.

\section{MATERIAL AND METHODS}

As a part of the documentation studies, inflorescence samples were collected randomly from four different districts of Kerala viz., Thiruvananthapuram, Pathanamthitta, Thrissur and Palakkad. The collected inflorescence samples were placed separately in polythene covers bearing details of sample number, date and place of collection. Infested samples were taken from diverse locations and got them labelled after individually separating the caterpillars.

They were thereafter provided with fresh inflorescence samples free of any other eggs or larvae. The morphological characters of larvae and time taken for pupation were later on recorded. The adults emerged from pupae were killed by using chloroform and pinned in the thoracic region with the aid of minuten pins. The wings of moths were stretched with the support of forceps and pins of convenient size. The setting of wings was done immediately, to avoid damage of specimens, loss of scales and inability to stretch the wings. Since many of them were microlepidopterans, they were double mounted to eliminate further damage. Plastazole foams $(2 \times 4 \times 15 \mathrm{~mm})$ were used to pin the specimens after proper setting. The well-arranged specimens were preserved with naphthalene balls and labelled, for identification by expert taxonomists.

\section{RESULTS AND DISCUSSION}

Mango panicle was infested with a complex of insect pests representing various orders of insects. Abundant number of lepidopteran infestation was recorded from the inflorescence samples. The samples collected were comprised of specimens belonging to various families of order Lepidoptera including Geometridae, Lycaenidae, Tortricidae, Nolidae, Noctuidae, Erebidae and Crambidae. Many individual larvae formed webbings whereas a few others were found inside boreholes made on peduncle and pedicel of flowers. Another common trend observed was the shift of shoot feeders to inflorescence.

The identified specimens are tabulated (Table 1) and the details regarding the specimens are depicted below:

Thalassodes nr. dissita: The larvae of Thalassodes nr. dissita, Geometridae; were light greenish in colour resembling the stalks of panicle with patch like dark reddish spots on the dorsal surface of the caterpillars (Fig. 1). The adult moths had dark green coloured wings (Fig. 2). Preetha (2013) reported Thalassodes $s p$. infesting mango from Kerala. 
Perixera illepidaria Guenee: The larvae of Perixera illepidaria Guenee, Geometridae, were recorded from inflorescence of mango grown in Kollengode area of Palakkad district. The larvae were loopers moving from one panicle to other by hanging on a silken thread formed by them. The larvae were yellowish to dark brown in colour with banded appearance. There were a lot of variation in the colour of larvae during different instars. The newly formed pupae were green in colour, which subsequently turned brown before emergence of adults. The adults were fawn coloured with small dots on the margins of both the wings (Fig. 3). The larvae were found voraciously feeding on the floral parts leaving the stalks behind. Kumar et al (2014) reported the severe outbreak of $P$. illepidaria on litchi grown in many parts of India. Soumya et al (2017) in a study conducted in the orchards located at Karnataka to ascertain the activity on two major varieties of mango viz., Alphonso and Totapuri, the attack of this looper pest was found more evident during the peak flowering period of mango.
Comostola laesaria (Walker): The caterpillar of Comostola laesaria (Walker), Geometridae, the red dotted emerald moth, is a looper of pale green or brown colour. The adult is light greenish coloured medium sized with reddish dots on the wings with slight orange coloured border. The pest incidence was severe in a few panicles while others showed a medium level of infestation. The adults took eight days for emergence from pupal stage (Fig. 4). Reddy et al (2018) reported that $C$. laesaria caused webbings while feeding on the flowers of mango inflorescence.

Eublemma spp.: Eublemma nr. quadripunctata, was a stout dirty white coloured specimen from Erebidae (Fig. 5). Eublemma versicolor Walker, Erebidae; was collected from Thrissur district (Fig. 6). The moths had a stout buff coloured body with a transverse brown coloured line running along the forewing and hindwing. The pupal case was hard and found having an outer cover of dried floral parts. Another two moth species from the family Erebidae, subfamily Boletobiinae, were reared, and the larvae had capitate setae spread all

Table 1. Lepidopterans documented from mango inflorescence

\begin{tabular}{|c|c|c|c|}
\hline Specimen & Family & Location & Co ordinates \\
\hline Thalassodes nr. dissita & $\begin{array}{l}\text { Geometridae } \\
\text { (Geometrinae) }\end{array}$ & Thiruvananthapuram & $\begin{array}{l}8^{\circ} 25^{\prime} 21.71^{\prime \prime} \mathrm{N}, \\
76^{\circ} 58^{\prime} 37.23^{\prime \prime} \mathrm{E}\end{array}$ \\
\hline Perixera illepidaria & $\begin{array}{l}\text { Geometridae } \\
\text { (Sterrhinae) }\end{array}$ & Palakkad & $\begin{array}{l}10^{\circ} 35^{\prime} 8.47716^{\prime \prime} \mathrm{N}, \\
76^{\circ} 43^{\prime} 43.61556 " \mathrm{E}\end{array}$ \\
\hline Comostola laesaria & $\begin{array}{l}\text { Geometridae } \\
\text { (Geometrinae) }\end{array}$ & Pathanamthitta & $\begin{array}{c}9^{\circ} 16^{\prime} 9.71904 " \mathrm{~N} \\
76^{\circ} 44^{\prime} 35.043^{\prime \prime} \mathrm{E}\end{array}$ \\
\hline Eublemma nr.quadripunctata & $\begin{array}{l}\text { Erebidae } \\
\text { (Boletobiinae) }\end{array}$ & Thiruvananthapuram & $\begin{array}{l}8^{\circ} 21^{\prime} 8.64 " \mathrm{~N}, \\
77^{\circ} 4^{\prime} 40.44^{\prime \prime} \mathrm{E}\end{array}$ \\
\hline Eublemma versicolor & $\begin{array}{l}\text { Erebidae } \\
\text { (Boletobiinae) }\end{array}$ & Thrissur & $\begin{array}{l}10^{\circ} 55^{\prime} 30.239 " \mathrm{~N} \\
76^{\circ} 29^{\prime} 05.494^{\prime \prime} \mathrm{E}\end{array}$ \\
\hline Eublemma sp. & $\begin{array}{l}\text { Erebidae } \\
\text { (Boletobiinae) }\end{array}$ & Thiruvananthapuram & $\begin{array}{c}8^{\circ} 25^{\prime} 29.90388 " \mathrm{~N}, \\
77^{\circ} 1 \text { '53. } 64588^{\prime \prime} \mathrm{E}\end{array}$ \\
\hline Eublemma abrupta & $\begin{array}{l}\text { Erebidae } \\
\text { (Boletobiinae) }\end{array}$ & Thiruvananthapuram & $\begin{array}{c}8^{\circ} 25^{\prime} 29.75376 " \mathrm{~N}, \\
77^{\circ} 1 \text { '53. } 2002 " \mathrm{E}\end{array}$ \\
\hline Lymantria nr.ampla & $\begin{array}{l}\text { Erebidae } \\
\text { (Lymantriinae) }\end{array}$ & Thiruvananthapuram & $\begin{array}{c}8^{\circ} 25^{\prime} 27.56712 " \mathrm{~N} \\
77^{\circ} 1 ' 52.55256 " \mathrm{E}\end{array}$ \\
\hline Lymantria sp. & $\begin{array}{l}\text { Erebidae } \\
\text { (Lymantriinae) }\end{array}$ & Thiruvananthapuram & $\begin{array}{c}8^{\circ} 25^{\prime} 27.56712 " \mathrm{~N} \\
77^{\circ} 1 ' 52.55256 " \mathrm{E}\end{array}$ \\
\hline Anthene lycaenina lycaenina & $\begin{array}{l}\text { Lycaenidae } \\
\text { (Lycaeninae) }\end{array}$ & Thiruvananthapuram & $\begin{array}{c}8^{\circ} 25^{\prime} 27.56712 " \mathrm{~N}, \\
77^{\circ} 1 ' 52.55256 " \mathrm{E}\end{array}$ \\
\hline Rapala manea & $\begin{array}{l}\text { Lycaenidae } \\
\text { (Lycaeninae) }\end{array}$ & Thiruvananthapuram & $\begin{array}{c}8^{\circ} 22^{\prime} 36.12 " \mathrm{~N}, \\
77^{\circ} 6^{\prime} 45.36^{\prime \prime} \mathrm{E}\end{array}$ \\
\hline Nanaguna breviuscula & Nolidae & Thrissur & $\begin{array}{l}10^{\circ} 55^{\prime} 30.239 " \mathrm{~N} \\
76^{\circ} 29^{\prime} 05.494^{\prime \prime} \mathrm{E}\end{array}$ \\
\hline Gatesclarkeana erotias & $\begin{array}{l}\text { Tortricidae } \\
\text { (Olethreutinae) }\end{array}$ & Pathanamthitta & $\begin{array}{c}9^{\circ} 16^{\prime} 9.71904 " \mathrm{~N} \\
76^{\circ} 44^{\prime} 35.043^{\prime \prime} \mathrm{E}\end{array}$ \\
\hline Archips micaceana & $\begin{array}{l}\text { Tortricidae } \\
\text { (Tortricinae) }\end{array}$ & Pathanamthitta & $\begin{array}{c}9^{\circ} 16^{\prime} 9.71904 " \mathrm{~N}, \\
76^{\circ} 44^{\prime} 35.043^{\prime \prime} \mathrm{E}\end{array}$ \\
\hline Aetholix flavibasalis & Crambidae & Thiruvananthapuram & $8^{\circ} 25^{\prime} 56.58755^{\prime \prime} \mathrm{N}$, \\
\hline Bombotelia jocosatrix & $\begin{array}{l}\text { Noctuidae } \\
\text { (Euteliinae) }\end{array}$ & Thiruvananthapuram & $\begin{array}{l}8^{\circ} 25^{\prime} 21.71 " \mathrm{~N}, \\
76^{\circ} 58^{\prime} 37.23^{\prime \prime} \mathrm{E}\end{array}$ \\
\hline Chlumetia transversa & $\begin{array}{l}\text { Noctuidae } \\
\text { (Euteliinae) }\end{array}$ & Thrissur & $\begin{array}{c}10^{\circ} 55^{\prime} 30.239 " \mathrm{~N}, \\
76^{\circ} 29^{\prime} 05.494^{\prime \prime} \mathrm{E}\end{array}$ \\
\hline
\end{tabular}


over the dorsal surface of the body with sparsely dispersed non capitate setae. The larva of Eublemma sp. is bright yellow in colour with brownish patches spreading all over the body (Fig. 7). Adult is dull coloured having a dual transverse line running along the wings and bordering the outer margin (Fig. 8). The larvae of Eublemma abrupta was blackish in colour with a yellow coloured ' $v$ ' shaped band near the head region and four eye like spots on the middle of dorsal surface (Fig. 9). The moths were dull brown coloured with dual transverse lines of bland white shade running towards the inner side of forewings and the hind wings had black dots towards the lower end (Fig. 10). Babu et al (2001) and Kaushik (2009) reported the infestation of Eublemma versicolor on mango inflorescence at its full bloom state. Yadav et al (2014) reported the incidence of $E$. angulifera M. from mango flowers in Kerala.

Lymantria spp.: Larvae of Lymantria nr. ampla Walker, Erebidae; a hairy caterpillar was collected from full bloom panicles of mango grown in the Nemom area of Thiruvananthapuram. The adult moth is slightly more than medium in size having a golden brown coloured forewings with brown and black patches on it. The hindwings are light brown in colour (Fig. 11). There were already reports regarding infestation of these pests from Kerala. Lymantria sp., another one from Erebidae family was collected from Nemom area of Thiruvananthapuram district. The larvae were hairy caterpillars. The adult moth was whitish in colour with blackish brown patches smeared all over the surface of forewings and hindwings. The antennae of the moth were unipectinate type (Fig.12).

Anthene lycaenina lycaenina: Anthene lycaenina lycaenina, Lycaenidae; infesting mango inflorescence was recorded from Athiyannur area of Thiruvananthapuram district. There were about 1-5 larvae per panicle. The larvae were stout reddish brown coloured with paired rows of yellowish pattern on the dorsal surface. The larvae in later instar stages were voracious feeders with only the stalks left behind.

Rapala manea (Hewitson): R. manea (Hewitson), Lycanidae, was observed infesting on the inflorescence of homestead grown mango trees from different areas of Thiruvananthapuram district. The stout dull yellowish larva showed spine like projections along the sides of the body and a dark reddish brown line over the dorsal surface in the two ends (Fig. 13). The early instar larva was found feeding on the floral parts while the later instars were more voracious feeders, only the stalks of the inflorescence remained. The adult males were dark winged with a tinge of purple colour (Fig. 14). Female moths were lighter in colour. The ventral side showed black coloured markings towards the anal angle with an orange colour topping. Robinson et al (2010) also reported mango as a host of $R$. manea.

Nanaguna breviuscula Walker: Nanaguna breviuscula Walker, Nolidae; was another caterpillar recorded from the inflorescence. The larva was translucent pale green yellowish in colour with light red coloured lines running along whole length of the body (Fig. 15). The larva had a brown coloured head. The adult moth was brownish in colour having a diffused blackish band on the forewings (Fig. 16). The hindwings were dull white coloured.

Gatesclarkeana erotias Meyrick: A wide range of moths belonging to Tortricidae were collected and reared from the inflorescence. Gatesclarkeana erotias Meyrick, Tortricidae; is a bell shaped moth reared from mango inflorescence. The larva is dark green coloured caterpillar with a brownish head (Fig. 17). The forewings are dark dull coloured with metallic reddish brown streaks and the hindwings are with dark yellowish coloured shade all over (Fig. 18).

Archips micaceana (Walker): The moths of Archips micaceana (Walker) had a bell shaped structure like most of the tortricid moths. The larvae were found feeding on the inflorescence. The moths were having reddish orange forewings with red coloured wavy lines in between. There were greyish markings on the inner side of light yellowish coloured hindwings (Fig. 19). Similar observations were recorded by Prakash et al (2002) in flowers of vanilla grown in Karnataka. The larvae webbed the flowers and bored the flower stalks which resulted in withering of vanilla flowers.

Aetholix flavibasalis Guenee: Aetholix flavibasalis Guenee, family Crambidae was collected from mango inflorescence of the trees grown in homestead of Athiyannur area of Thiruvananthapuram district. The moths had a medium body. The forewings were purplish in colour with pale spots. There was a white band across the hind wings (Fig. 20). Sundararaju (2009) reported the incidence of $A$. flavibasalis from cashew.

Bombotelia jocosatrix Guenee : The larvae of Bombotelia jocosatrix Guenee, Noctuidae; was found feeding on flowers of mango grown in a homestead located at Athiyannur block of Thiruvananthapuram. The larvae of these moths are stout, light greenish in colour with dark reddish pink tinges towards the anal region (Fig. 21). The adult has blackish brown forewings; the margin of each of the forewing has an arc cut out of the tornus (Fig. 22). The hindwings are white with a central black spot and a broad dark border. The moth has an unusual resting posture. Crest of scales are found raised over the head, the abdomen curled up over the body. The fifth instar larva was collected, which pupated within two days. The pupal period was for 11 days.

Chlumetia transversa Walker: The larva of Chlumetia 

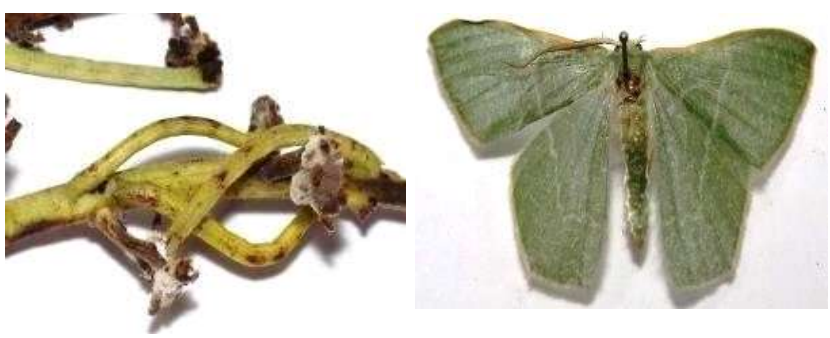

Fig. 1. Larva - Thalassodes Fig. 2. Adult - Thalassodes nr. nr. dissita

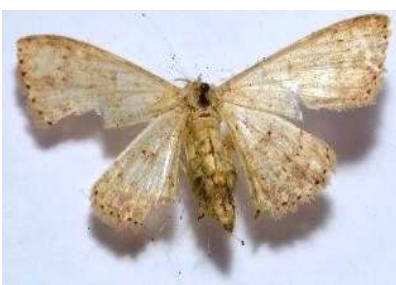

Fig. 3. Perixera illepidaria

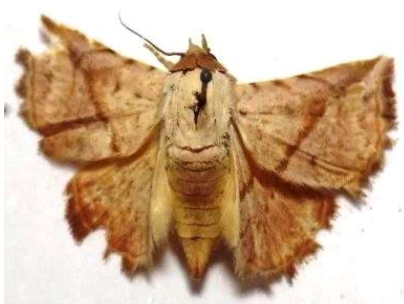

Fig. 5. Eublemma nr. quadripunctata

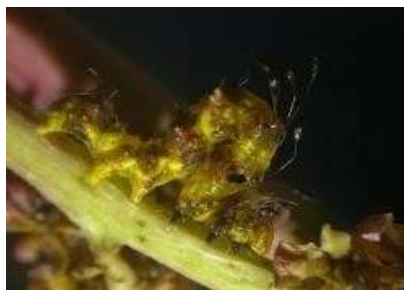

Fig. 7. Larva - Eublemma sp. Fig. 8. Adult- Eublemma sp.

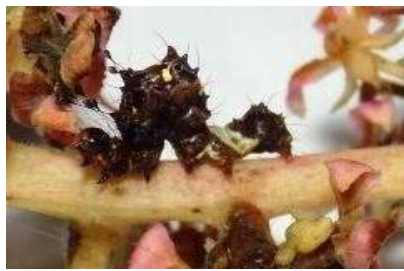

Fig. 9. Larva - Eublemma abrupta

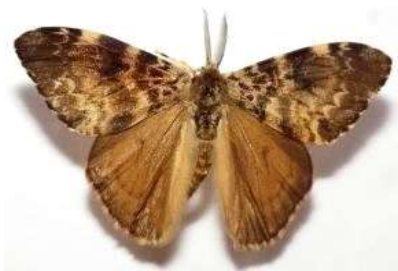

Fig. 11. Lymantria nr.ampla
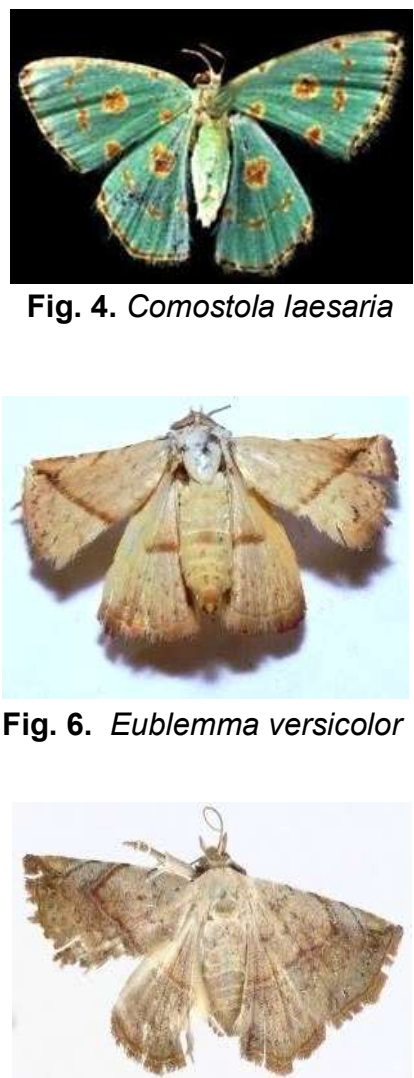

Fig. 4. Comostola laesaria

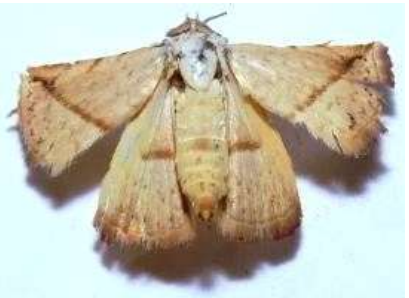

Fig. 6. Eublemma versicolor

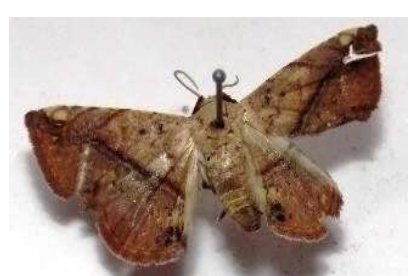
abrupta

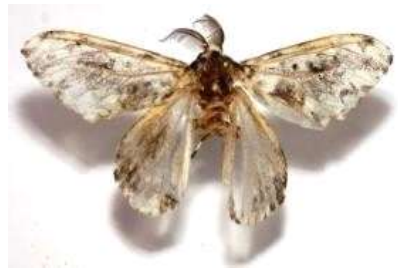

Fig. 12. Lymantria $\mathrm{sp}$
Fig. 10. Adult - Eublemma

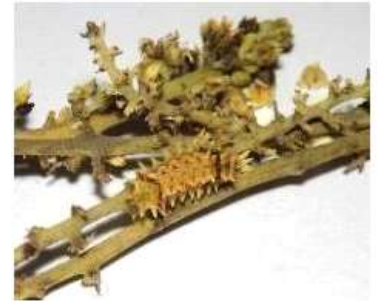

Fig. 13. Larva - Rapala manea

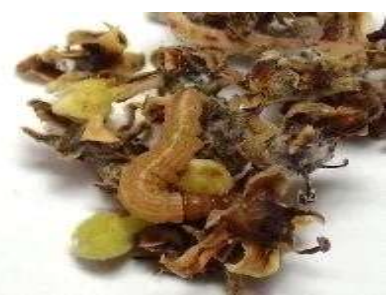

Fig. 15. Larva- Nanaguna breviuscula

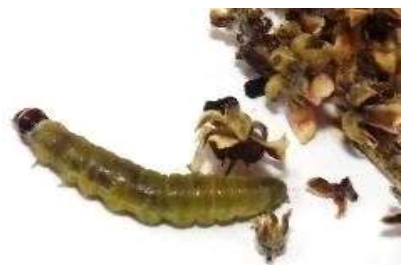

Fig. 17. Larva- Gatesclarkeana erotias

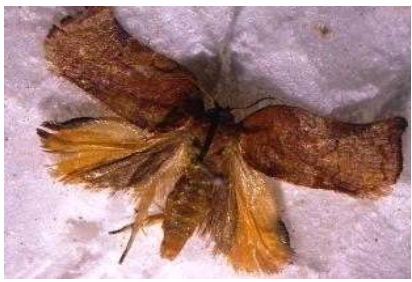

Fig. 19. Archips micaceana

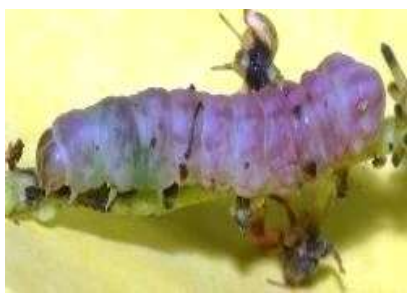

Fig. 21. Larva - Bombotelia jocosatrix

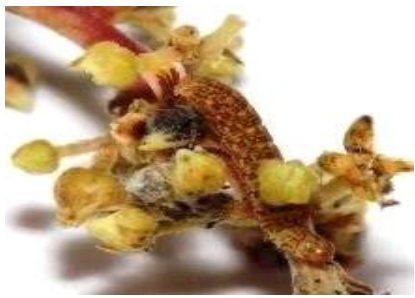

Fig. 23. Larva - Chlumetia transversa

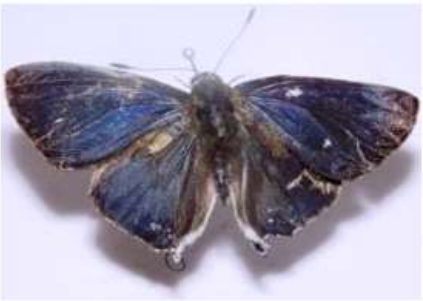

Fig. 14. Adult - Rapala manea

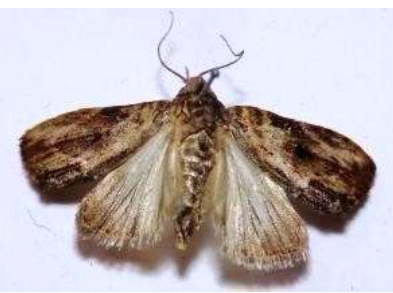

Fig. 16. Adult - Nanaguna breviuscula

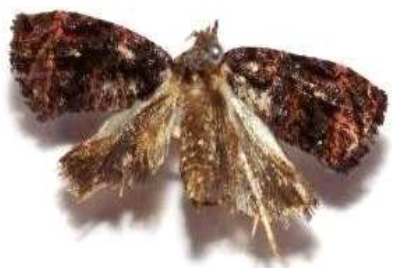

Fig. 18. Adult - Gatesclarkeana erotias

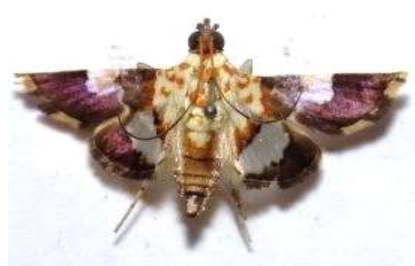

Fig. 20. Aetholix flavibasalis

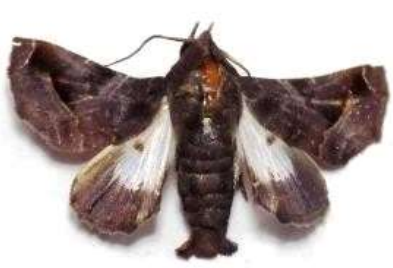

Fig. 22. Adult - Bombotelia jocosatrix

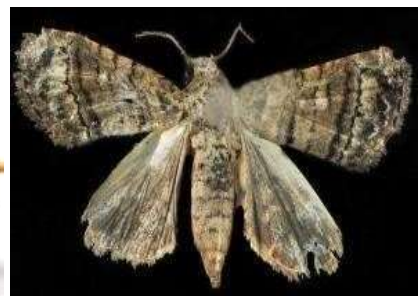

Fig. 24. Adult - Chlumetia transversa 
transversa Walker, Noctuidae was another caterpillar pest, found infesting the peduncle and pedicles of flowers with boreholes. The larva is yellowish with peculiar red coloured pattern on the dorsal surface (Fig. 23). The adults emerged within six days of pupal period. The adult moth has shining greyish brown coloured forewings and hind wings. The submarginal bands on the fore wings were found broken (Fig. 24). This pest infest all the varieties of mango, with considerable damage caused by boring of shoots (Singh and Kaur 2014). The symptoms of damage exhibited by this pest was similar to one recorded by Soumya et al (2017). Reddy et al (2018) reported the incidence of shoot borers in mango including C. transversa and Gatesclarkeana erotias.

\section{CONCLUSION}

The infestation level and species composition of lepidopterans on the mango panicle vary with season and climatic conditions. But, the threat to reproductive phase of the crop, caused by these caterpillars cannot be neglected.

\section{ACKNOWLEDGEMENT}

The authors are grateful to Kerala Agricultural University for offering funds for the successful completion of the research work.

\section{REFERENCES}

Babu BL, Maheshwari TU and Venugopal RT 2001. Pest complex and their succession on mango, Mangifera indica in Peninsular India. Indian Journal of Entomology 63(2): 158-162.

Dangi KK, Singh AK, Varan R and Jain VK 2017. Characterization of different mango cultivars for fruit set and yield. Indian Journal of

Received 30 October, 2021; Accepted 19 January, 2022
Ecology 44(6): 751-754.

Jayanthi PD, Nagaraja T, Raghava T, Kempraj V, Mala BR and Shashank PR 2018. Lepidopterans found aggressively devouring mango panicles: A paradigm shift in pest status. Pest Management in Horticultural Ecosystems 24(2): 96-100.

Kapadia MN 2003. Insect pests of mango and their management. In: National Seminar on Mango, June14-152003, GAU, Junagadh.

Kaushik DK 2009. Relative preference of different mango varieties by major insect pests with special reference to mango hopper and its management through new insecticide molecules. Ph. D thesis, Indira Gandhi Krishi Vishwavidyalaya, Raipur, India.

Kumar V, Reddy PVR, Anal AKD and Nath V 2014. Outbreak of the looper, Perixera illepidaria (Lepidoptera: Geometridae) on litchi, Litchi chinensis (Sapindales: Sapindaceae): A new pest record from India. Florida Entomologist 97(1): 22-29.

Prakash KV, Sudarshan MR and Radhika NS 2002. Studies on insect pests of vanilla in Karnataka, pp. 592-595. In: Proceedings of the 15th Plantation Crops Symposium Placrosym XV, Mysore, India, 10-13 December, 2002. Central Coffee Research Institute, Coffee Research Station, Karnataka, India.

Preetha L 2013. Shoot Feeders of mango and their management. M.Sc. (Ag.) thesis, Department of Agricultural Entomology, Kerala Agricultural University, Thrissur, Kerala, India.

Reddy PVR, Gundappa B and Chakravarthy AK 2018. Pests of mango, Springer, Singapore, $440 \mathrm{p}$.

Robinson GS, Ackery PR, Kitching IJ, Beccaloni GW and Hernández LM 2010. HOSTS-a database of the world's Lepidopteran host plants, Natural History Museum, London, 150p.

Singh S and Kaur G 2014. Diversity of pestiferous borers of mango in Punjab. Indian Journal of Applied Entomology 28(2): 125-127.

Soumya BR, Verghese A and Jayanthi PK 2017. Diversity and economic status of Lepidopteran insect-pest on two major varieties of mango. Journal of Entomology and Zoology Studies 5: 838-843

Sundararaju D 2009. Species composition, yield loss and management of lepidopteran flower and fruit pests in cashew. Journal of Plantation Crops 37(1): 21-25.

Yadav ES, Bangarwa KS, Dhankhar SS and Pannu RK 2014. Major insect pests of fruit crops and their management. Entomology and Nematology 4(1):169. 